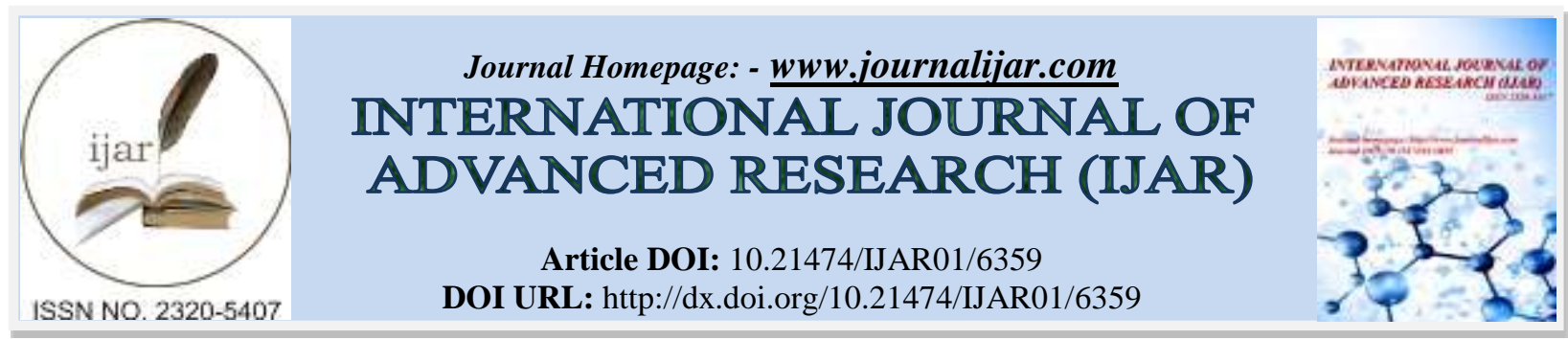

RESEARCH ARTICLE

\title{
PATIENT PERCEPTIONS OF BENEFITS RECEIVED DURING SHORT-TERM GLOBAL HEALTH TRIPS.
}

"Judella Haddad-Lacle ${ }^{1}$, Charles Haddad ${ }^{1}$, Leslie Ravago ${ }^{1}$ and Lori Bilello ${ }^{2}$.

1. University of Florida College of Medicine-Jacksonville, Department of Community Health and Family Medicine.

2. University of Florida College of Medicine-Jacksonville, Department of Medicine.

\section{Manuscript Info}

\section{Manuscript History}

Received: 20 November 2017

Final Accepted: 22 December 2017

Published: January 2018

\section{Key words:-}

Short- term medical mission trips,

Global Health, Underserved

International communities. Patient perceptions.

\section{Abstract}

Global health short-term medical mission trips to San Francisco de Macoris, Dominican Republic have been provided by the $1^{\text {st }}, 2^{\text {nd }}$ year medical students and pharmacy students from the University of Florida for the past 15 years. The trip is named DR SALUD (Dominican Republic Health). These trips provide basic preventive medical and minor surgical care to patients in underserved communities in rural areas of San Francisco de Macoris, Dominican Republic. There are currently few studies available that examine the recipients perceptions of these programs. This study was done to investigate the perceptions of the recipient patients on the benefit they receive from the services of University of Florida students during the short -term medical mission trip.

A survey containing 6 questions aimed to understand the perception of the recipients during the short-term global health trips was administered and assessed. Our findings revealed nearly all of the patients, 98.9\% felt that participating in the UF DR Salud was beneficial to their health. Furthermore, $99.4 \%$ of patients plan to return next year.

Copy Right, IJAR, 2018,. All rights reserved.

\section{Introduction:-}

Global health short-term medical missions are well-established means of providing health care to the developing world. ${ }^{1}$

Global health trips for American medical students are being offered more frequently and by more medical schools . ${ }^{2 .}$ These trips aim to address unmet health care need of low-and middle-income countries. ${ }^{3}$

Despite increasing numbers of short-term medical missions to dispatch humanitarian healthcare, extensive investigations on how recipient patients perceive short-term medical mission are lacking., 5

This study focused on the perception of the recipient patient to asses if they felt that these trips were beneficial or harmful to their health. The trip named DR SALUD (Dominican Republic Health) is a short-term medical mission trip that consists of $1^{\text {st }}$ and $2^{\text {nd }}$ year medical students, pharmacy students and attending physicians. They participate during their global health rotation during their spring break, traveling to San Francisco de Macoris, Dominican Republic. These trips have been on going for the past 15 years. Even though we believe the recipients are receiving 
benefits from these trips, there is no data or study to support this belief.

The goal of this study was to determine the perceived benefits or harm by the recipients during these short-term medical mission trips. We also wanted to investigate what areas needed improvement for the upcoming year or areas where the patient population felt additional help could be provided.

Some research studies question if the short-term medical mission trips cause more harm than good. Common criticisms include unsafe practices, lack of consideration for cultural differences, lack of coordination with the host country, unfamiliarity with the language and unsustainable treatments. ${ }^{6}$

\section{Methods:-}

DR SALUD is a short-term medical mission trip. This is a 5-day rotation to several rural areas of San Francisco de Macoris, Dominican Republic provided by $1^{\text {st }}$ and $2^{\text {nd }}$ year students from the University of Florida and supervised by attending physicians. Once the team arrives at the rural community, students are grouped into several different stations. The recipient participant registers at the intake station and is triaged and directed to specific stations for their care. Stations included Internal Medicine, Gynecology, Pediatrics, Minor surgical procedures and Public Health.

In Public Health recipients receive several educational session including smoking cessation, vision check for reading glasses, fluoride dental treatment for all children up to the age of 18 years, breast feeding and sexually transmitted infection prevention.

Once the participants are done at their station they are given a pharmacy slip to obtain vitamins and medications, if indicated. All participants receive at least 2 months worth of vitamins.

Inclusion criteria for this study was participants 18 years and older. Subjects included both female and male.

A 6 question questionnaire was given to the participants while they were waiting for their medications at the pharmacy hold station after care was provided. University of Florida students conducted the questionnaire in Spanish with the participants. The study was conducted in all 5 rural areas. This questionnaire was anonymous so no protected health information was accessed. No consent was needed.

\section{Results:-}

There were a total of 730 surveys completed in the 5 sites, ranging from a low of 95 surveys at one site to a high of 199 surveys at the busiest site. The majority of the patients $(55.1 \%)$ have participated in a DR SALUD free clinic in the past. $33.6 \%$ who have been to a clinic in the past one time, $35.1 \%$ twice, $16.9 \%$ three times, and $10.2 \%$ more than three times (Table 1).

Nearly all of the patients $(98.9 \%)$ felt that the visit to a DR SALUD clinic was helpful to their health and $99.4 \%$ of patients plan to come back next year. Only one person from all 5 clinics felt that their visit to the clinic was harmful, but did not clarify what they felt the harm was. When patients were asked what was the most beneficial service provided at the clinic, $40.7 \%$ said medications, $20.8 \%$ vitamins, $20.8 \%$ public health advice, $10.0 \%$ fluoride treatments, $4.3 \%$ surgical procedures and $3.3 \%$ of patients had multiple responses. These responses varied by clinic site - even though patients from all clinic sites felt that medications were the most beneficial, the second most beneficial service varied by clinic site. Patients from three of the clinics felt that vitamins were the next most beneficial service while two of the sites reported that public health advice was the second most beneficial service (Figure 2).

Table 1:- Survey results - all clinic sites

\begin{tabular}{|l|l|}
\hline Have you received care from DR SALUD clinics in the past? & $\mathrm{N}=730$ \\
\hline Yes & $402(55.1 \%)$ \\
\hline No & $328(44.9 \%)$ \\
\hline If yes, how many times have you participated? & $135(33.6 \%)$ \\
\hline 1 time & \\
\hline
\end{tabular}




\begin{tabular}{|l|l|}
\hline 2 times & $141(35.1 \%)$ \\
\hline 3 times & $68(16.9 \%)$ \\
\hline 3 times & $41(10.2 \%)$ \\
\hline No response & $17(4.2 \%)$ \\
\hline Do you feel these trips are helpful to your health? & \\
\hline Yes & $722(98.9 \%)$ \\
\hline No & $2(0.3 \%)$ \\
\hline No response & $6(0.8 \%)$ \\
\hline What do you feel is the most beneficial reason you come back? & \\
\hline Medications & $297(40.7 \%)$ \\
\hline Vitamins & $152(20.8 \%)$ \\
\hline Public Health Advice & $152(20.8 \%)$ \\
\hline Flouride Treatments & $73(10.0 \%)$ \\
\hline Surgical Procedures & $31(4.3 \%)$ \\
\hline Multiple responses & $24(3.3 \%)$ \\
\hline No response & $1(0.1 \%)$ \\
\hline Will you come back next year? & \\
\hline Yes & $726(99.4 \%)$ \\
\hline No & $2(0.3 \%)$ \\
\hline No response & $2(0.3 \%)$ \\
\hline Do you feel any harm has been caused by these trips? & \\
\hline Yes & $1(0.1 \%)$ \\
\hline No & $725(99.3 \%)$ \\
\hline No response & $4(0.6 \%)$ \\
\hline
\end{tabular}

Figure 1:- Most beneficial services by site

What Do You Feel is the Most Beneficial Reason You Came Back?

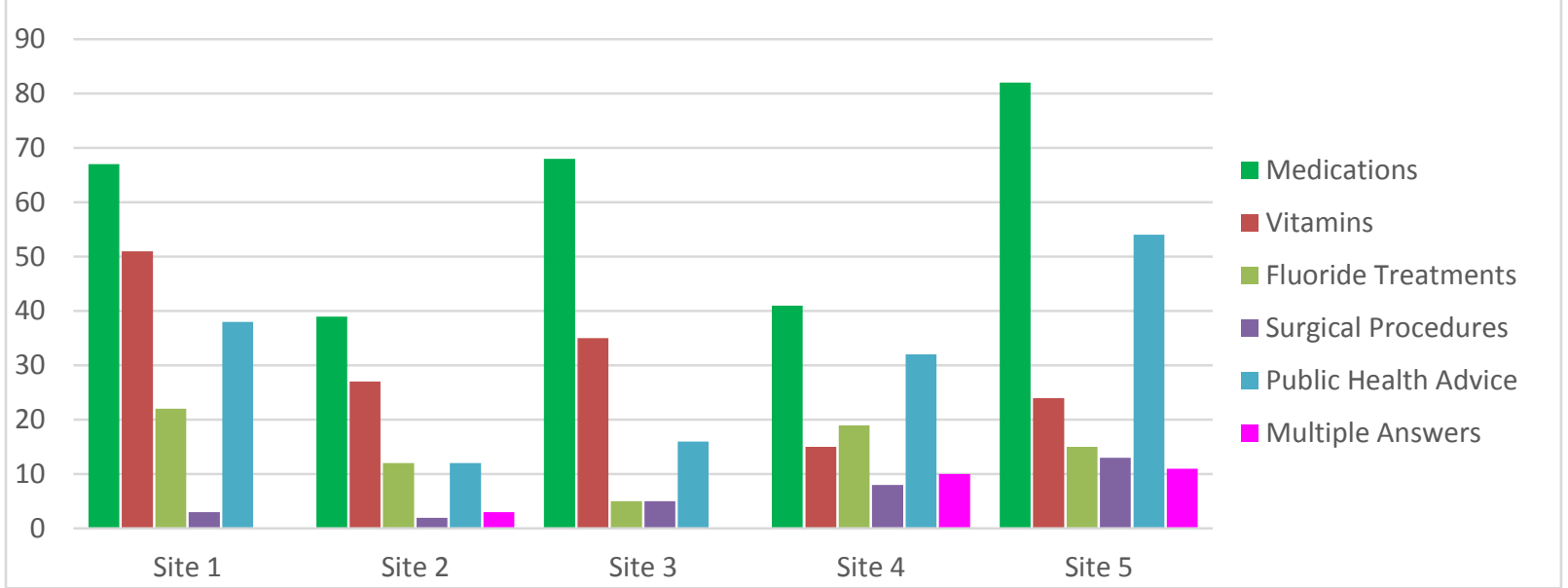

\section{Discussion:-}

Our findings revealed that nearly all of the patients felt that the visit to UF DR Salud global health clinic was helpful to their health. As physicians, our most important goal is to do no harm to our patients. Even though we did not feel that harm was being done, we wanted to reaffirm this through the patient's perceptions of the care that they receive. Perception of doing harm could be perceived due to limited resources available to us and patient care being offered by medical students. In all the sites medications seems to be the most beneficial reason that the patients came back. Since we have been coming annually for several years we try to provide consistency in the type and amount of medications we take with us. Sites 4 and 5 are the farthest away from any hospital facility due to their location. Therefore, the surgical procedures offered, which are unavailable to them locally, motivated patients to come back. In site 5 we also noted a high response to public health advice as the reason to come back. At this site we donated a 
large number of reading glasses to the patients, which the population included teachers and older people. The patient population at this site has difficulty leaving their homes due to the mountainous location and limited transportation.

\section{Conclusion:-}

Short-term medical mission trips are being offered by more medical schools to help patients in underserved areas and provide medical students with a clinical and cultural experience. There is very limited information on the perspective of care provided to patients by the medical mission group. Our study confirms the perception that nearly all patients interviewed felt that the short-term medical mission trips were helpful to their health.

\section{Reference:-}

1. Maki J, Qualls M, White B, Kleefield S, Crone R.Health impact assessment ands short-term medical missions: a methods study to evaluate quality of care.BMC Health Serv Res. 2008;8:121.

2. Ravago Leslie, Haddad Charles, Haddad-Lacle Judella, Kockler Virginia, Devos Elizabeth, Bilello Lori. Impact of global medical service trips on physician careers. International Journal of Recent Scientific research.2017;8(3): 15826-15829.

3. Sykes KJ, Short-term medical service trips: a systematic review of the evidence. AM J Public Health. 2014; 104(7): 38-48.

4. Weng YH, Chiou HY, Tu CC, Liao ST, Bhembe PT, Yang CY, Chiu YW. Survey of patient perceptions towards short-term mobile medical aid for those living in a medically underserved area of Swaziland. BMC Health Serv Res. 2015;15:524.

5. DeCamp M, Enumah S, O`Neill D, Sugarman J. Perceptions of a short-term medical programme in the Dominican Republic:voices of care recipients, Glob Public Health 2014;9(4):411-25.

6. Hawkins J. Potential Pitfalls of Short-Term Medical Mission. Journal of Chrisitian Nursing 2013; 30(4): 1-6 